\title{
DIIJITAL ÖRNEK OLAYA DAYALI ÖĞRENME YAKLAŞIMININ ÖĞRETMEN ADAYLARININ AKDADEMIK GÜDÜLENMELERI ÜZERINNDEKİ ETKISI
}

\author{
Fatih SALTAN \\ Meltem AKIN KÖSTERELIOĞLLU \\ İlker KÖSTERELIOĞLL
}

\begin{abstract}
Atıf/O: Saltan, Fatih; Akın Kösterelioğlu, Meltem; Kösterelioğlu, İlker (2016). Dijital Örnek Olaya Dayalı Öğrenme Yaklaşımının Öğretmen Adaylarının Akademik Güdülenmeleri Üzerindeki Etkisi, Hitit Üniversitesi Sosyal Bilimler Enstitüsü Dergisi, Yıl 9, Sayı 2, Aralık 2016, ss. 809-820
\end{abstract}

Özet: Bu araştırmanın amacı örnek olay yönteminin 3.sinıfta eğitim gören öğretmen adaylarinin akademik güdülenme düzeylerine etkisini belirlemektir. Çalışmada öntest-sontest kontrol gruplu deneysel model kullanılmuştır. Toplamda 138 öğretmen adayından oluşan her iki gruba da sinıf yönetimi dersi geleneksel öğretim yaklaşımlar takip edilerek aynı ögretim üyesi tarafinda anlatılmıştır. Yalnızca deney grubu ögrrencilerinin eğitimi 8 hafta boyunca dijital ortamda örnek olaya dayalt uygulamalarıla desteklenmiştir. Uygulama öncesinde ve sonrasinda tüm katılımcılara "Akademik Güdülenme Ölçeği" uygulanmıştır. Gruplar arasındaki değişim farklılıklarını aynı anda görmek için karışık ölçümler için iki faktörlü ANOVA tekniği kullanılmıştır. Analizler sonucu sınıf öğretmenliği programında ögrrenim gören ögrretmen adaylarinın son test puanları artış gösterirken bu değişikliğin anlamlı bir fark yaratmadığ görülmüştür. Din kültürü ve ahlak bilgisi öğretmenliği programinda öğrenim gören ögrrencilerde ise akademik güdülenme düzeyleri öntest ve sontest puanlarında değişim göstermemiştir. Bunun yanı sira ortak grupetkisi araştırıldığında da gruplar arasında anlamlı bir farklılığa yol açmadiğr görülmüş̧ür.

Anahtar Kelimeler: Örnek olay, Problem dayalı öğrenme, Akademik güdülenme

Makale Geliş Tarihi: 06 06. 2016/ Makale Kabul Tarihi: 01.12.2016

* Bu araştırma Amasya Üniversitesi SEB-BAP 15/041 nolu proje kapsaminda desteklenmiştir ve araştırmanın bulgular Viyana / Avusturya'da düzenlenen Conference of the International Journal of Arts \& Sciences'da sözlü bildiri olarak sunulmuştur.

1 Yrd. Doç. Dr. Amasya Üniversitesi Eğitim Fakültesi, fsaltan@gmail.com

2 Yrd. Doç. Dr. Amasya Üniversitesi Eğitim Fakültesi, mkostereli@hotmail.com

3 Yrd. Doç. Dr. Amasya Üniversitesi Eğitim Fakültesi, ikostereli@hotmail.com 


\section{The Effect of Digital Case-Based Learning on Pre-service Teachers' Academic Motivation Levels*}

Citation/(): Saltan, Fatih; Akın Kösterelioğlu, Meltem; Kösterelioğlu, İlker (2016). The Effect of Digital Case-Based Learning on Pre-service Teachers' Academic Motivation Levels, Hitit University Journal of Social Sciences Institute, Year 9, Issue 2, December 2016, pp. 809-820

Abstract: The purpose of this study was to identify the effect of case method on the academic motivation levels of third year teacher candidates. The study utilized pretest-posttest control group design. Both groups were taught the course by the same instructor using traditional teaching approaches. Treatment group students were supported by web aided case-based learning implementations for 8 weeks. "Academic Motivation Scale" were given to all participants prior and subsequent to implementation. In order to identify whether there were significant differences between treatment and control groups based on pre and post test results, Two-Way ANOVA for Mixed Measures technique was used to observe variances in change. The results showed that Primary School Teaching Program teacher candidates' academic motivation levels were increased in post test. However, this difference was not significant. Religious Culture and Moral Education Teaching Program teacher candidates' academic motivation levels did not change in pre and post test scores. Measurement effect and group interaction effect were also examined for both groups, however, it was not found to generate significant differences between groups. In this sense, it can be claimed that case based learning method that was implemented to treatment groups did not generate a significant difference in academic motivation.

Keywords: Case-based Learning, Problem-based learning, Academic motivation

\section{GİİŞ}

Çağdaş eğitim sistemi eğitim programları, sınıf yönetimi, denetim, öğrenme öğretme süreci gibi pek çok alanda yenilikler getirmiştir. Söz konusu yeniliklerden birisinin de öğrenme ve öğretme sürecinde kullanılan yöntem ve tekniklerle ilgili olduğu söylenebilir. Çağdaş eğitim sistemi öğrenme ve öğretme sürecinde öğrencinin aktif rol oynayabileceği bazı yöntemlerin kullanılmasın öngörmektedir. Bu yöntemlerden birisi olan örnek olay yöntemi, öğrencileri gerçek yaşam sorunlarıla karşı karşıya getiren bir yöntem olup daha önceden öğrenilen kavram ve ilkelerin gerçekleşmiş veya gerçekleşmesi muhtemel olaylar üzerinde uygulamaya koyulmasıyla öğrenme öğretme sürecinde kuram ve uygulama arasındaki boşluğun doldurulmasına yardımcı olmayı hedeflemektedir(Sönmez,2004:284). 
İlk olarak 1870'lerde Harvard Law School'da kullanılmaya başlayan örnek olay yöntemi(Case-based learning method; CBL) öğrencilerin gerçek yaşamda karşılaşabilecekleri sorunlu bir olayı sınıf ortamında çözmeleri esasına dayanmaktadır (Jonassen, 2004: 52). Dolayısıyla bu yöntemde öğrencilerin karşılaşacakları olası soruna yönelik bir olaya aktif olarak katılmaları ve olayın nedenleri hakkında fikirler ve çözüm önerileri üretmeleri beklenmektedir (Saban, 2004: 264). Örnek olay yönteminin amac1, mutlak doğruları bulmaktan ziyade eldeki verileri kullanarak çözüm önerileri üretebilmek, bunları farklı düşünceye sahip kişiler karşısında savunabilmek, karşısındakini ikna edebilmek, gerektiğinde başkalarının düşüncelerinden yararlanarak yeni düşünceler oluşturmaya çalışmak olarak ifade edilmektedir. Bu yöntem aktif ve yansıtıcı öğrenmeyi kolaylaştırarak eleştirel düşünme ve etkili problem çözme becerilerinin gelişmesine neden olan katılımcı bir öğrenme süreci sağlamaktadır (Tomey,2003:36). Olaya dayalı öğrenme metodu öğrenme ve öğretim süreci bilişsel ve sosyal yapılandırmacı modellerini harmanlayarak, öğrenme sürecinin aktif ve interaktif bileşenlerini ön plana çıkarmaktadır (Mayo,2004:138). Bu yöntem bazı bilim alanlarının yanı sıra etkili öğretmen eğitiminde de kullanılabilmektedir. Örnek olaylar, teori ve uygulamalarla bağlantılı olabilecek konu ve problemlerle ilişkili ve gerçek yaşamı yansıtan durumlar olduğu için öğretmen eğitiminde geleneksel yöntemlerden daha etkili olarak kullanılabilirler (Ball ve Cohen,1999 ve Shulman,1992'den akt. Yalçınkaya, 2010: 38).

Gelişen teknolojilerle birlikte diğer öğretim yöntemlerinde olduğu gibi örnek olaya dayalı öğretim yöntemide farklı teknolojilerle birlikte yürütülmeye başlanmıştır. Örnek olaylarınmetin olarak öğrencilere sunulmasının yanı sıra sesli veya görüntülü olarak da hazırlanarak tıp, hukuk ve sosyal bilimler dâhil olmak üzere birçok alanda kullanılmaktadır (Choi ve Lee, 2009: 100). Öte yandan öğrenci erişimini genişletmek adına web tabanlı (web-based) ve mobil uygulamalarda gelişim göstermiştir (bknz. Bronack ve diğerleri., 1999: 305; Lee ve Choi ,2009: 100; Roushias, 2005: 43). Örnek olay yöntemi (Case Base Learning, CBL) alışık olduğumuz geleneksel sınıf ortamlarından dijital ortamlara taşınmıştır. Bu bağlamda ortaya çıkan bu yeni yaklaşım "Digital CBL", "Electornik CBL", "Online CB"L veya "Web-based CBL" olarak nitelendirilebilmektedir.

Öğrenme öğretme sürecinde öğrencinin öğrenmesinde etkili olan faktörlerden birisi öğretim yöntemi olmakla birlikte yöntemin tek başına yeterli olduğu söylenemez. Öğrencinin ön öğrenmeleri, hazır bulunuşluk düzeyi, sınıf ortamının yanı sıra öğrenmede etkili olabilecek diğer bir önemli faktör de 
güdülenmedir. Keller'e (2000: 2) göre motivasyon (güdülenme), öğrencinin öğrenmeye istek duymasını sağlayan çaba ve içsel bir güç olarak görülebilir. Güdülenme, kaynağını öğrencinin kendisine ve çevresine ilişkin algılarından alan öğrenciyi, öğrenmesi amacıyla kendisine sunulan eğitsel etkinliğe odaklayan ve onu tamamlama kararlılığ kazandıran bir olgudur (Viau, 2015: 5). Bu bağlamda akademik güdülenme akademik aktiviteler için gereken enerjinin üretilmesi olarak tanımlanabilirken bu enerjinin kaynağına ilişkin farkl1 görüşler mevcuttur (Bozanoğlu,2004:84). Güdülenme, okuldaki öğrenci davranışlarının yönünü, şiddetini, kararlılığını ve eğitim ortamlarında istenilen amaca ulaşmada hızı belirleyen önemli güç kaynaklarından biridir. Okulda ve sınıfta gözlenen öğrenme güçlüklerinin ve disiplin olaylarının büyük bir kısmının kaynağının güdülenme ile ilgili olduğu düşünülmektedir (Akbaba, 2006: 343).

Öğrencinin güdülenmesini etkileyen pek çok faktör vardır. Bu faktörleri Viau (2015: 8) öğrencinin özgeçmişi (aile, arkadaş ve ön çalışmalar), toplum (değerler, kültür), Okulla ilgili faktörler (mevzuat), sinıfla ilgili faktörler (öğretmen, değerlendirme etkinlikleri, sınıf iklimi, ödül ve yaptırımlar, eğitsel etkinlikler) şeklinde sınıflandırmaktadır. Bütün bu faktörlerin önemli olması yanında özellikle sınıfla ilgili faktörler tüm öğrencilerin güdülenmeüzerinde birinci derecede rol oynamaktadır. Bu faktörlerden de özellikle eğitsel etkinlikler özel bir önem taşımaktadır. Genel olarak eğitim etkinlikleri sınıfta işlenen bir ders boyunca dinleme ve alıştırmalar yapma, bir proje üzerinde grup çalışması yapma, rapor yazma, ödev yapma, ders çalışmagibi yollarla öğretmen ve öğrenci arasındaki etkileşimden ibarettir.

\section{A. Araştırmanın Amacı}

Yeni öğretim yaklaşımları ve öğrencileri güdülemek bir arada düşünüldüğünde, dijital olarak sunulanörnek olaya dayalı öğrenme metodunun öğrencilerin akademik güdülenmeleri üzerindeetkili olabileceği düşünülmüştür. Bu amaçla yürütülen araştırmanın amacı örnek olay yönteminin 3. sınıfta eğitim gören öğretmen adaylarının akademik güdülenme düzeylerine etkisini belirlemektir. Aşağıdaki araştırma soruları çalışmaya yön vermiştir;

1- Dijitalolarak sunulan örnek olaya dayalı öğrenme yönteminin uygulandığı deney ve geleneksel yöntemlerin uygulandığ1 kontrol gruplarının akademik güdülenme düzeylerinin ön test ve son test puan ortalamaları nedir?

2- Deney ve kontrol gruplarındaki öğretmen adaylarının akademik güdülenme düzeyleri arasında anlamlı farklılık var mıdır? 


\section{YÖNTEM}

Olaya dayalı öğrenme yönteminin öğretmen adaylarının akademik güdülenme düzeyine olan etkisinin araştırıldığ gruplu deneysel model kullanılmıştır (Fraenkel, Wallen \& Hyun, 2011: 269).

\section{A. Çalışma Grubu}

Araştırmanın çalışma grubunu 2015-2016 eğitim- öğretim yılının bahar döneminde sınıf yönetimi dersini alan sınıf öğretmenliğiprogramı (SÖP) (N=74) ve Din kültürü ve ahlak bilgisi eğitimi programında (DKAB) öğrenim gören ( $N=64)$ 3. sınıf öğrencileri oluşturmaktadır. Her iki bölüm içerisinde deney ve kontrol grupları ayrı ayrı oluşturulmuştur.

\section{B. Uygulama}

$\mathrm{Bu}$ çalışmabahar yarıyılındadeney ve kontrol grubunda ki tüm öğrencilerin öğretmenlik eğitiminde zorunlu olarak okutulan sınıf yönetimi dersini alırken yürütülmüştür. Her iki gruba da ders geleneksel yaklaşımlar takip edilerek aynı hoca tarafında anlatılmıştır. Yalnızca deney grubu öğrencilerinin eğitimi8 hafta boyunca dijital olarak sunulan örnek olaya dayalı öğrenme uygulamalarıyla desteklenmiştir. Her hafta öğrenciler bir örnek olayı izlemiş ve incelemişlerdir. Gösterilen örnek olaylar, sınıf yönetimi konularına bağlı olarak gerçek hayattan alınmış olayların uzman öğretmen yetiştiricileritarafından senaryolaştırılarak video filme dönüştürülmesiyle oluşmuştur. Öğrenciler kendi kullanıc1 adı ve şifreleriyle hazırlanan web sayfasına (bkz.ornekolay. amasya.edu.tr) erişmiş video tabanlı örnek olayları izleyip 8 basamaktan oluşan problem çözme aşamalarını takip etmişlerdir (Saltan \& Özden, 2010). Bu adımlar şu şekildedir; (1) Problemi tanımlama, (2) Durumla ilgili gerçeklikleri ve bakış açılarını tanıma (3) Uzman görüşü alma, (4) Çözüm havuzu oluşturma, (5) Çözümlerin avantaj ve sınırlılıklarını karşılaştırma, (6) Önerileri yazma (7) Akranlarının çözüm önerilerini değerlendirme, (8) Kendi önerisini gözden geçirme. 
Figure 1. Öğrenci ekranı

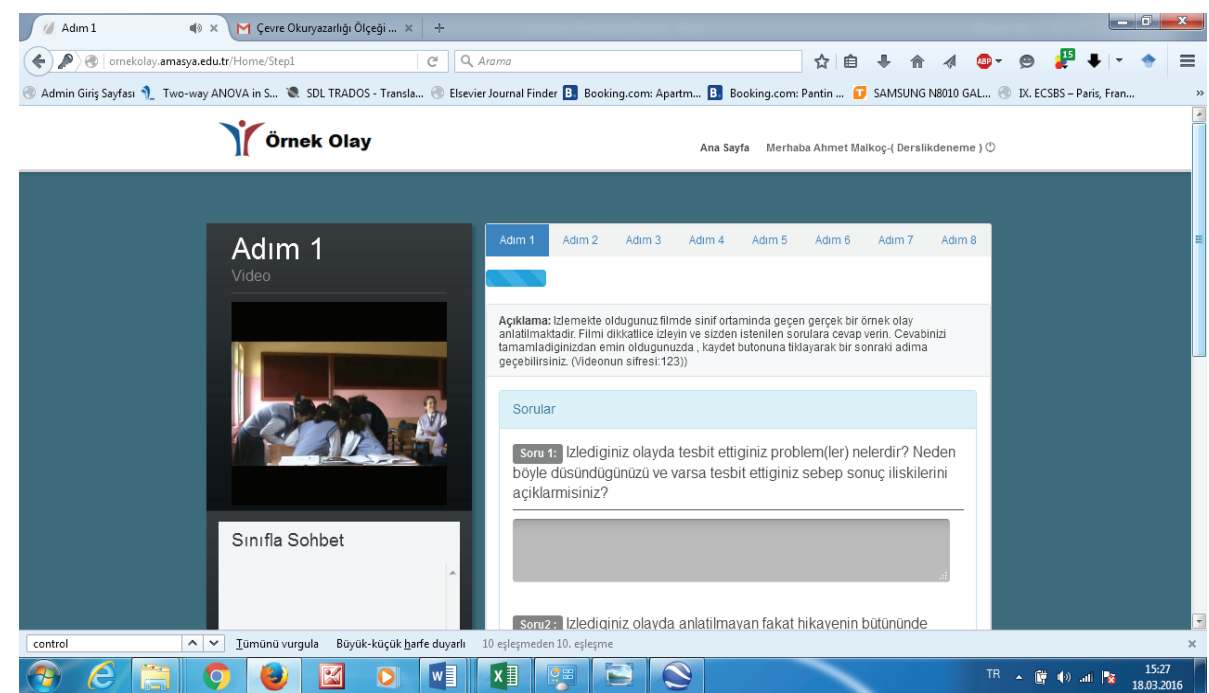

Tüm bu adımlar yürütülürken dersin hocası kendi kullanıcı ve şifresiyle websayfasına bağlanarak öğrencilerinin ilerleyişleri takip etmiştir (bknz. Figure 2). Uygulama boyunca ders hocası öğrencilere rehberlik etmiş ve onları görüşlerini ifade etmeleri yönünde cesaretlendirmiştir.

Figure2. Öğretmen ekran1

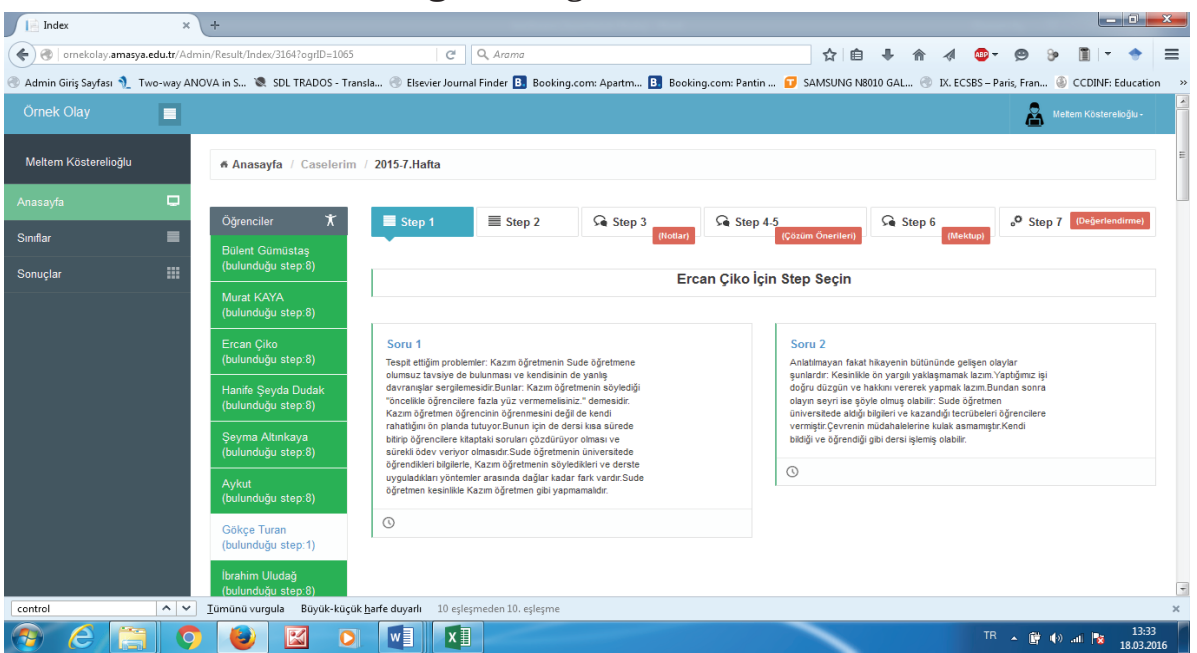

\section{VerilerinToplanmas1}

Uygulama öncesinde ve sonrasında tüm katılımcılara Bozanoğlu (2004:94) tarafından geliştirilen "Akademik Güdülenme Ölçeği” uygulanmıştır. 20 maddeden oluşan ölçekteki her bir madde yanıtlayıcıya kendisine uygun olup

814 Hitit Üniversitesi Sosyal Bilimler Enstitüsü Dergisi - Yıl 9, Sayı 2, Aralk 2016 
olmadığı bakımından Likert tipi 5'li dereceleme şeklinde sunulmuştur. Ölçeğin geliştirilme aşamasındaki Cronbach - Alpha değeri .85 olarak bulunmuştur. $\mathrm{Bu}$ araştırmada ise ölçeğin Cronbah-Alpha değeri .91 olarak tespit edilmiştir

\section{Verilerin Analizi}

Araştırma kapsamında elde edilen veriler analizindekullanılan istatistiksel teknikler deney ve kontrol gruplarının kendi içindeöntest ve sontest sonuçlarında akademik güdülenme puanları arasında anlamlı birfarklılık olup olmadığını belirlemek için ilişkili örneklemler t-Testi kullanılmıştır. Deney ve kontrol grupları arasında öntest ve sontest sonuçlarındaakademik güdülenme puanları arasında anlamlı bir farklılık olup olmadığınıbelirlemek için ilişkisiz örneklemler t-Testi kullanılmıştır. Ayrıca deney ve kontrol grupları arasında öntest vesontest sonuçlarına göre anlamlı bir farklılık olup olmadığ belirlenmekistenmiştir. Bu durumda gruplar arasındaki değişim farklılıklarını aynı andagörmek için karışık ölçümler için iki faktörlü ANOVA tekniği kullanılmıştır. Analizlerin tamamı SPSS 20 istatistik programı kullanılarak yapilmıştır.

\section{BULGULAR}

Dijital olarak sunulan örnek olaya dayalı öğrenme yönteminin uygulandığ deney grubunun ve geleneksel yöntemlerin uygulandığı kontrol grubunun akademik güdülenme düzeyleri öntest ve sontest puanlarının ortalamalarına ilişkin sonuçlar Tablo 1'de verilmiştir.

Tablo 1.Deney ve Kontrol Gruplarının Akademik Güdülenme Puanlarının Ortalama ve Standart Sapma Değerleri

\begin{tabular}{|c|c|c|c|c|c|c|c|}
\hline \multirow{2}{*}{ Gruplar } & & \multicolumn{3}{|c|}{ ÖNTEST } & \multicolumn{3}{|c|}{ SONTEST } \\
\hline & & $\mathbf{N}$ & $\mathbf{M}$ & $\mathbf{S}$ & $\mathbf{N}$ & $\mathbf{M}$ & $\mathbf{S}$ \\
\hline \multirow{2}{*}{ SÖP } & Deney & 37 & 76.19 & 10.56 & 37 & 80.26 & 10.41 \\
\hline & Kontrol & 37 & 74.03 & 11.24 & 37 & 76.19 & 10.56 \\
\hline \multirow{2}{*}{ DKAB } & Deney & 32 & 72.47 & 11.03 & 32 & 72.12 & 11.19 \\
\hline & Kontrol & 32 & 73.56 & 14.26 & 32 & 71.23 & 15.35 \\
\hline
\end{tabular}

Tablo 1'de görüldüğü üzere SÖP programında öğrenim gören öğrencilerden deney grubunda yer alan öğretmen adaylarının akademik güdülenme düzeylerinin akademik ortalama değeri uygulama öncesinde $M=76.19$ iken uygulama sonrasinda $\mathrm{M}=80.26$ olmuştur. Kontrol grubunda ise $\mathrm{M}=74.03$ 'ten 
M=76.19'a yükselmiştir. Bu sonuçlara göre SÖP'de öğrenim gören deney ve kontrol grubundaki öğretmen adaylarının akademik güdülenme düzeylerinin arttı̆̆ı söylenebilir.

DKAB programında öğrenim gören öğrencilerden deney grubunda yer alan öğretmen adaylarının akademik güdülenme düzeylerinin akademik ortalama değeri uygulama öncesinde $M=72,47$ iken uygulama sonrasinda $M=72,12$ olduğu kontrol grubunda ise bu değişikliğin $M=73,56$ 'dan $M=71$,23'e düştüğü görülmüştür. Buna göre DKAB programında öğrenim gören öğretmen adaylarından deney grubunda yer alanların akademik güdülenme düzeyleri çok fazla değişmezken kontrol grubundaki öğretmen adaylarının akademik güdülenme düzeylerinin düştüğü görülmektedir.

Deney ve kontrol grubunda yer alan öğretmen adaylarının akademik güdülenme düzeylerinin öntest ve sontest puanları arasındaki değişimlerin anlamlı bir fark gösterip göstermediğine ilişkin iki faktörlü ANOVA sonuçları Tablo 2'de verilmiştir.

Tablo 2. Deney ve Kontrol Gruplarının Akademik Güdülenme Puanlarına İlişkin Öntest veSontest Puanlarına İlişkin ANOVA Sonuçları

\begin{tabular}{|c|c|c|c|c|c|c|}
\hline Gruplar & $\begin{array}{l}\text { Varyansın } \\
\text { Kaynağ1 }\end{array}$ & $\mathbf{K T}$ & sd & Ko & $\mathbf{F}$ & $\mathbf{p}$ \\
\hline \multirow{8}{*}{ SÖP } & Deneklerarası & 11897.732 & 73 & & \multirow{3}{*}{2.244} & \multirow{3}{*}{.139} \\
\hline & $\begin{array}{l}\text { Grup } \quad \text { (Deney/ } \\
\text { Kontrol) }\end{array}$ & 359.594 & 1 & 359.594 & & \\
\hline & Hata & 11538.138 & 72 & 160.252 & & \\
\hline & Denekleriçi & 5327.38 & 74 & & & \\
\hline & $\begin{array}{l}\text { Ölçüm } \\
\text { (Öntest/Sontest) }\end{array}$ & 359.594 & 1 & 359.594 & 5.247 & .025 \\
\hline & Grup*Ölçüm & 33.768 & 1 & 33.768 & .493 & .485 \\
\hline & Hata & 4934.018 & 72 & 68.528 & & \\
\hline & Toplam & 17225.112 & 147 & & & \\
\hline \multirow{8}{*}{ DKAB } & Denekleraras1 & 1765.605 & 63 & & \multirow{4}{*}{.001} & \multirow{4}{*}{.974} \\
\hline & $\begin{array}{l}\text { Grup (Deney/ } \\
\text { Kontrol) }\end{array}$ & .304 & 1 & .304 & & \\
\hline & Hata & 1765.301 & 62 & 284.924 & & \\
\hline & Denekleriçi & 3683.791 & 64 & & & \\
\hline & $\begin{array}{l}\text { Ölçüm } \\
\text { (Öntest/Sontest) }\end{array}$ & 57.467 & 1 & 57.467 & .991 & .323 \\
\hline & Grup*Ölçüm & 31.766 & 1 & 31.766 & .548 & .462 \\
\hline & Hata & 3594.558 & 62 & 57.977 & & \\
\hline & Toplam & 5449.396 & 127 & & & \\
\hline
\end{tabular}

Tablo 2 incelendiğinde Sınıf öğretmenliği programında öğrenim gören öğretmen adaylarının akademik güdülenme düzeylerinin uygulama öncesinden sonrasına anlamlı bir fark göstermediği görülmektedir $\left[\mathrm{F}_{1,72}=.493, \mathrm{p}>.001\right]$.

816 Hitit Üniversitesi Sosyal Bilimler Enstitüsü Dergisi - Yıl 9, Sayı 2, Aralk 2016 
Benzer şekilde Din kültürü ve ahlak bilgisi öğretmenliği programında öğrenim gören öğretmen adaylarının da uygulama öncesinden sonrasına akademik güdülenme düzeylerinin anlamlı bir şekilde değişmediği saptanmıştır $\left[\mathrm{F}_{1,62}=.548, \mathrm{p}>.001\right]$. Bu bulgulara bağlı olarak örnek olaya dayalı öğrenme uygulamasının her iki programda öğrenim gören öğretmen adaylarının akademik güdülenme düzeylerini arttırmada anlamlı bir etkiye sahip olmadığ sonucuna varılmıştır.

\section{TARTIŞMA VE SONUÇ}

Araştırma bulguları dijital olarak sunulan örnek olaya dayalı öğrenme yönteminin öğretmen adaylarının akademik güdülenme düzeyleri üzerinde anlamlı bir fark yaratmadığını göstermektedir. Bu bulgunun aksine literatürdefarklı alanlarda örnek olaya dayalı öğrenme yönteminin katılımcıların güdülenmeleri üzerindeki olumlu etkisi gösterilmiştir. Örneğin, Saral (2008: 73) örnek olaya dayalı öğrenmenin onuncu sınıf lise öğrencilerinin insanda üreme sistemi konusunu öğrenmelerine ve güdülenmelerine katkısın1 araştırdığı çalışmasında örnek olaya dayalı öğrenmenin öğrencilerin akademik başarılarını ve güdülenmelerini arttırdığını saptamıştır. Benzer şekilde Yoo, Park ve Lee (2010: 863) örnek olaya dayalı olarak sunulan videoların hemşirelik öğrencilerinin klinikte karar alma ve öğrenme motivasyonları üzerindeki etkisini belirlemek için araştırma yürütmüşlerdir. Bu araştırmada da video destekli örnek olayların sunumunun etkili olduğu saptanmıştır. Yoo ve Park (2015: 166) hemşirelik öğrencileriyle yaptıkları farklı bir çalışmada, örnek olaya dayalı öğrenme yönteminin öğrencilerin iletişim becerisi, problem çözme becerisi ve öğrenme motivasyonlarına etkisini araştırmış ve uygulanan yöntemin söz konusu değişkenler üzerinde anlamlı bir etkiye sahip olduğunu belirtmişlerdir.

Yalçınkaya (2010: 195) tarafından "Örnek olaya dayalı öğrenme yönteminin onuncu sınıf öğrencilerinin gazlar konusu ile ilgili kavramları anlamalarına, tutumuna ve motivasyonuna etkisi” konulu tez çalışmasında söz konusu yöntemin öğrencilerin kimyayakarşı tutumlarını ve motivasyonlarını geliştirmede etkili olduğu sonucuna ulaşmıştır. Baeten, Dochy, Struyven (2013: 484) tarafından yapılan araştırmada ise örnek olaya dayalı öğrenme yönteminin öğrencilere kademeli olarak tanıtılması ve motivasyon için algılanan desteğin önemi vurgulanmıştır.

Öte yandan öğrenme ve öğretme sürecinde kullanılan yöntemler öğrencilerin motivasyonunu etkileyebilecek pek çok faktörden sadece biridir. Diğer faktörler 
öğretmen tarafindan ancak sınırlı düzeyde kontrol altında tutulabilmektedir (Viau, 2015: 9). Dolayısıyla araştırma bulgularında örnek olaya dayalı öğrenme yöntemininakademik güdülenme üzerinde anlamlı bir etkiye sahip olmamasının nedeni akademik güdülenmeyi etkileyebilecek diğer faktörlerin etki derecesinin kullanılan öğrenme yönteminden daha yüksek düzeyde olduğu düşünülebilir. Bu araştırmada farklı sonuçlar elde edilmesinin diğer bir nedeni olaya dayalı öğrenmenin web ortamında yürütülmüş olmasından kaynaklanmış olabilir. Web tabanlı eğitime alışık olmayan öğrencilerin bu ortamda kendilerine sunulan örnek olaylara ilişkin tutumları ve kendilerinden beklenen uygulamalara katılım sağlamadaki istekliliği elde edilen sonuçları etkilemiş olabilir. Öte yandan, araştırmalar ABD de birçok öğretmenin mesleklerinin ilk 6 yılında karşılaştıkları problemleri çözemedikleri için mesleklerini bıraktığını göstermektedir (Deryakulu, 2005: 36). Bu açıdan bakıldığında örnek olayları otantik ve gerçek olaylara dayalı olması öğretmen adaylarının ne gibi problemlerle karışlacaklarını daha iyi görmelerine ve olumsuz yönde etkilenmelerine sebep olduğu düşünülebilir.

\section{Öneriler}

Sınıf öğretmenliği programında öğrenim gören öğretmen adaylarının akademik güdülenme düzeylerinin ön test ve son test puan ortalamaları karşılaştırıldığında son testte artış gösterirken bu değişikliğin anlamlı bir fark yaratmadığ1 görülmüştür. Din kültürü ve ahlak bilgisi öğretmenliği programında öğrenim gören öğrencilerde ise akademik güdülenme düzeyleri öntest ve sontest puanlarında değişim göstermemiştir. Ayrıca her iki grupta da ölçüm ve grup ortak etkisi araştırılmış ancak bu etkinin de gruplar arasında anlamlı bir farklılığa yol açmadığı görülmüştür. Bu bağlamda deney gruplarına uygulanan olaya dayalı öğrenme yönteminin akademik güdülenmede anlamlı farklılı̆ga neden olmamıştır.

Sonraki yapılacak çalışmalarda şu konulara odaklanılabilir;

1- Örnek olayların incelenmesinde takip edilen problem çözme aşamalarının her bir basamağının öğrencinin algısı ve güdülenmeleri üzerindeki etkisine daha ayrıntılı araştırılabilir.

2- Öğrencilere izlettirilen örnek olayların her birinin etkisine daha yakından bakılabilir. Seçilen çarpıcı/uç örneklerin öğrencilerin güdülenmesini nasıl etkilediği irdelenebilir.

3- Öğrencilerin genel olarak motivasyonlarının yanı sıra sadece uygulamanın yürütüldüğü derse karşı olan tutum ve algıları incelenebilir. 


\section{KAYNAKÇA}

AKBABA, Sırrı. (2006). Eğitimde Motivasyon. Kazım Karabekir Eğitim Fakültesi Dergisi, S.13, ss.362-372.

BAETEN, Marlies., DOCHY, Filip. \& STRUYVEN, Katrien. (2013). The effects of different learning environments on students' motivation for learning and their achievement. British Journal of Educational Psychology, S.83, pp.484-501.

BOZANOĞLU, İhsan. (2004). Akademik güdülenme ölçeği: Geliştirilmesi, geçerliği ve güvenirliği. Ankara Üniversitesi. Eğitim Bilimleri Fakültesi Dergisi, S.37, ss.8398.

BRONACK, Stephen. C., Kilbane, Clare. R., Herbert, Joanne. M., \& MCNERGNEY, Robert. F. (1999). In-service and pre-service teachers' perceptions of a Web-based, case-based learning environment. Journal of Information Technology for Teacher Education, 8(3), pp.305-320.

CHOİ, Ikseon. \& LEE, Kyunghwa. (2009). Designing and implementing a casebased learning environment for enhancing ill-structured problem solving: classroom management problems for prospective teachers. Education Technology Research Development 57, pp.99-129.

DERYAKULU, Deniz. (2005). Bilgisayar Öğretmenlerinin Tükenmişlik Düzeylerinin İncelenmesi. Eurasian Journal of Educational Research, S.19, ss.35-53.

FRAENKEL, Jack. R., Wallen, Norman. E., \& HYUN, Helen. H. (20011). How to Design and Evaluate Research in Education. Eighth Edition. New York: McGraw-Hill.

JONASSEN, David. H. (2004). Learning to solve problems: an instructional design guide. San Francisco, Pfeiffer

KELLER, John. (2000). How to integrate learner motivation planning into lesson planning: the ARCS model approach. https://pantherfile.uwm. edu / simonec/public/ Motivation\%20retention\%20articles / Articles / KelleriIntegrateMotivationIntoLessonPlans.pdf adresinden 16 Mart 2016 tarihinde edinilmiştir.

LEE, Kyunghwa. \& CHOİ, Ikseon. (2008) Learning Classroom Management Through Web-Based Case Instruction: Implications for Early Childhood Teacher Education. Early Childhood Educ J, S.35, pp.495-503.

MAYO, Joseph. A. (2004). Using Case-Based Instruction To Bridge The Gap Between Theory And Practice In Psychology Of Adjustment. Journal of Constructivist Psychology, 17:137-146, 2004 Copyright, Taylor \& Francis Inc. ISSN: 10720537 print / 1521-0650 online DOI: 10.1080/107205304902739174

MOON SOOK, Yoo. \& HYUNG-RAN, Park. (2015). Effects of case-based learning on communication skills, problem-solving ability, and learning motivation in nursing students. Nursing \& Health Sciences. 7(2), pp.166-72. doi: 10.1111/ nhs. 12151.

MOON SOOK, Yoo., JINN-HEE, Park., \& Si-RA, Lee. (2010). The effects of case-based learning using video on clinical decision making and learning motivation in undergraduate nursing students. Journal of Korean Academy of Nursing. 40(6): pp. 863-71. doi: 10.4040/jkan.2010.40.6.863.

ROUSHİAS, Christos. (2005). The Design and Development of a Multimedia Casebased Environment: PARENTS. Unpublished Dissertation. Columbia University, USA. 
SABAN, Ahmet. (2004). Öğrenme öğretme süreci yeni teori ve yaklaşımlar. 3. Baskı. Ankara: Nobel Yayınc1lı

SALTAN, Fatih, \& Özden M. Yaşar. (2010). Designing a Case-based Instruction Model for Web-based Teacher Education. Soceity for Information Technology \& Teacher Education. In Society for Information Technology \& Teacher Education International Conference (Vol. 2010, No. 1, pp. 831-837).

SARAL, Sevim. (2008). The Effect Of Case Based Learning On Tenth Grade Students' Understanding Of Human Reproductive System And Their Perceived Motivation. Orta Doğu Teknik Üniversitesi Yayımlanmamış Yüksek Lsans Tezi, Ankara.

SÖNMEZ, Veysel. (2004). Program Geliş̧tirmede Öğretmen El Kitabı. 11.Baskı. Ankara: Pegem Akademi.

TOMEY-MARRINER, Ann. (2003). Learning withcases. TheJournal of Continuing Education in Nursing. 34(1), pp.34-38. DOI: 10.3928/0022-0124-20030101-07

VİAU, Rolland. (2015). Okulda Motivasyon. Çev. Yusuf Budak. Ankara: Anı Yayıncılık

YALÇINKAYA, Eylem. (2010). Effect Of Case Based Learning On 10th Grade Students' Understanding Of Gas Concepts, Their Attitude And Motivation. Orta Doğu Teknik Üniversitesi Yayımlanmamış Doktora Tezi, Ankara. 